\title{
Factors Affecting Nurse Students' Perception Regarding Role Transition at Faculty of Nursing - Benha University
}

\author{
* Rabab Mahmoud Hassan, Rehab Mohammed Rashad, Mona El-Tukhy Adly Barak, \\ Nursing Administration, Faculty of Nursing, Ain Shams University, Nursing Administration, \\ Faculty of Nursing, Benha University, Clinical Instructor in technical institute of Nursing, Benha \\ University.
}

\begin{abstract}
Background: Transition from nursing student to staff nurse can be exciting, stressful and challenging. Aim: aim of this study was to assess nurse students' perception regarding role transition at faculty of nursing - Benha University. Design: a descriptive research design was utilized to meet the aim of this study. The sample of this study included 193 out from 370 nurse students who selected randomly. Tools: tool for data collection: factors affecting role transition questionnaire. Results and Conclusion: More than two thirds of nurse students had moderate agreement level regarding organizational factors, also more than half of nurse students had moderate agreement level regarding personal and educational factors. Recommendation: Creating healthy environment is highly needed for new nurses during role transition. Conduct an orientation program for nursing students before internship year is very beneficial and prior each clinical training area to explain objectives, responsibilities and discuss nurse students' expectations.
\end{abstract}

Key words: Factors, Nurse students' perception, role transition.

\section{Introduction}

The profession of nursing has been no exception in feeling the need for responding to this scientific revolution. However, often the impact of science and technology is obvious to students as they prepare for practice and mastery of the basics of care (Kelly and Aern, 2009). Preparation of transition fundamentally deals with acquiring the basic knowledge of transition- related incidents and effective strategies for managing those (Meleis, 2010).

Nurse students are often unaware of the level of responsibility required from them as nurses and the lack of confidence in their ability to make clinical judgment. Nurse students are expected to translate knowledge, principles, and theories learned in college into their practice for the patients' population. Nurse students need time and experience to develop confidence, learn responsibility, think critically, and be able to make decision about patient care. The quality of nurse students' performance results from gaining knowledge and skills (Jessica and Crossman, 2015).

The initial movement from student to staff was termed by as a period of separation that causes uncertainty and anxiety among new graduates. So the 
readiness of new graduates to function as registered nurses continues to be in question. The need to assure an ongoing supply of competent registered nurses who are prepared to practice in acute care settings and who will remain in those settings requires a change in how new graduate nurses are transitioned into professional nurses (O'Shea and Kelly, 2007).

Transition from nurse student to practicing nurse can be problematic issue during which the graduate nurse needs to learn how to function independently in the rapidly changing and fast-paced healthcare environment, while the newly qualified nurses often feel poorly prepared for the role of staff nurse there for, supportive measures are needed to reduce stress during the transition period. (Jessica and Crossman, 2015).

Role transition begins during the graduate educational program when students are socialized into the role. The transition does not complete until later in the first year of practice. To facilitate and support their transition, students are expected to be orientated to their new role and to receive regular feedback from colleagues and line managers (MatenSpeksnijder et al., 2015).

There are several aspects which directly influence the transition process such as personal attributes, values and beliefs, the ability to reason, skills set and underpinning knowledge. One major stressor for the new nurse graduate is stressors leading to job dissatisfaction include work/personal life balance. These stressors have pushed new graduates to feel reality shock and leave their first job as a registered nurse (Lee et al., 2014).

Assisting newly qualified nurses during this transition time and to deal with issues that arise, healthcare facilities and education providers offer a multitude of educational strategies such as programs, preceptorship and workshops, which aimed to guide development from novice to advanced beginner practitioner (Parker et al., 2014).

Employees generally need assistance in two areas, the first is the specific skills and knowledge requirements for their role and the second is values and attitudes that organization given with any role. Role expectations can be clarified by using role models, role repetition, preceptors, mentors, when the nurse students understanding that they become able to meet the needs of the parties requesting care and works according to the professional standards and values. Consequence of role ambiguity, insufficient experience, lack of confidence, feeling with responsibility the gap between theory and practice lead to inadequate preparation of student nurses for the professional practice role, as a result of all that the shock happened (MacLellan et al., 2014).

\section{Significance of the study}

There is a rising concern among the nursing faculties and nursing administrators in both developing and developed countries about difficulties facing new nursing graduates in meeting professional requirements and adjusting to their new work role, even after intense educational preparation and clinical training (Bennett et al., 2012).

Transition period is characterized by anxiety, stress and manifestation of separation. The core of the transition problem is the shock of the nurse students when encountered with the real situation and discovering that their perception about actual working area differed from academic education. Therefore, this study will be conducted to assess factors affecting nurse students' perception 
regarding role transition at faculty of nursing -Benha University.

\section{Aim of the study}

This study aims to assess factors affecting nurse students' perception regarding role transition at faculty of nursing -Benha University through:

- Identifying factors affect nurse student perception about role transition.

\section{Research Question.}

- What are the factors which effect on nurse students' role transition?

\section{Subjects And Methods}

The methodology of the current study will be portrayed according to the following four designs:

- Technical design.

- Operational design.

- Administrative design.

- $\quad$ Statistical design.

\section{I- Technical Design}

The technical design includes study design, study setting, subjects and methods and tools that used in data collection.

Research Design: Descriptive research study was utilized to conduct this study.

Setting: The study was conducted at faculty of nursing at Benha University. It was established at 1993, accredited at 2016 and it contains six scientific departments namely, medical surgical department, pediatric department, maternal and neonate health department, administration department, psychiatry department and community health nursing department.

Subjects: A random sample was taken from $4^{\text {th }}$ year nursing students $(370$ students) who succeeded in the third year 2015-2016. The subject was 193 student including both males and females students at the first term of academic year 2016-2017. Type of sample calculation of selection: $n=N / 1+(e) 2$

(N=total student number, $370 \&$ $\mathrm{e}=0.05)($ Edwards, 2013)

Tools of data collection: Data for this study was collected by using one tool namely.

Factors affecting Role Transition Questionnaire: - It developed by (Azimian et al., 2014) and modified by the researcher. It includes (72) items, divided into 8 categories which included personal factors (14 items), social factors (4 items), students satisfaction factors (5 items), educational factors (9 items), organizational factors (24 items), expected level of support factors (5 items), professional accountability and commitment factors (9 items), nursing staff shortage factors ( 2 items).

Scoring system: Responses of nurse students were measured on a three points Likert Scale as follow, 2(Agree), 1 (Neutral), 0 (Disagree). The scores for each area of the items were summed up and the total divided by the number of the items, giving a mean score for the part. These scores were converted into a percent score. The total factors score was considered high if the percent score was equal or more than $75 \%$, moderate if the percent score was ranged from $60 \%$ 
to $75 \%$, while it considered low if the percent score less than $60 \%$.

\section{Operational Design}

The operational design includes the preparatory phase, pilot study and field work.

Preparatory phase: This phase started from December 2015 to March 2016. It included the following:

A review of the past, current related literature covering various aspects of the problem was done, using available books, articles, periodicals, and journals to get acquainted with the research problem.

Validity of tools: Content validity was tested by jury group consist of seven experts on nursing administration and community health nursing, two assistant professors of administration from Tanta University, three assistant professors of administration from Monofia University and two assistant professors of community from Benha University. Necessary modification was done according to jury opinions.

Reliability of study tool: It was measured using Cronbach's. Alpha coefficient, it was $(0$.752) for factors contributing to nurse students' perception.

Pilot study: Pilot study was conducted on 20 students who represent $10 \%$ of total participants to assess tool clarity and applicability. While there was no modification in tools, those who share in pilot study were included in the main study sample. It has also served in estimating the time needed for filling the form. It ranged between $30-40$ minutes.

Field work: The field work started from the beginning of October
2016 to the end of November 2016. The researcher met nursing students and explained the aim and the nature of the study and the method of filling questionnaire. Data was collected three days per week from faculty of nursing at Benha University. The questionnaire sheet was distributed during break time and between lectures in class rooms or at the end of the day. The time needed to filling questionnaire sheet ranged from (30:40) minutes. The average number of completed questionnaire daily ranged from 7-9 questionnaires.

\section{Ethical considerations:}

Before conducting the study, the respondent rights was protected by ensuring voluntary participation, so the informed consent was obtained from each participant after explaining the aim of the study, its potential benefits, methods for filling data collection tools and expected outcomes. The respondent rights to withdraw from the study at any time were assured. Confidentiality of data obtained was protected by allocation code number to the questionnaire sheet. Subjects were informed that the content of the tool used for the research purpose only.

\section{Administrative Design}

An official permission for data collection was directed from dean of faculty of nursing at Benha University to head of nursing service administration and psychiatric nursing departments for informing them about the aim and its expected outcomes to facilitate the data collection phase.

\section{Statistical Design}

After completion of data collection, computerized data entry and statistical analysis were fulfilling scored using Statistical Package for Social 
Science (SPSS) (Version 16.0). Descriptive statistics were applied in the form of mean and standard deviation for quantitative variables and frequency \& percentage for qualitative variables. The p-value is the degree is significant. Significance were determined by using FET $=$ Fisher Exact Test. The p- value is the probability that an observed difference is due to chance and not a true difference. A significance level value was considered when $\mathrm{p}$-value $\leq 0.05$ and a highly significance level was considered when $\mathrm{p}$-value $\leq 0.001$, while $\mathrm{p}$ - value $>$ 0.05 indicates non- significance results.

\section{Results}

Table (1): In relation to characteristics of studied sample, this table shows that less than two thirds of nurse students had age equal or more than 22 years old. Regarding to the gender, more than three quarters of nurse students were females. While about two thirds of nurse students had secondary education before faculty enrolment.

Figure (1): Shows that more than three quarters of nurse students $(75.6 \%)$ were single, while only $(24.4 \%)$ were married.

Figure (2): Clarifies the majority of nurse students $(81.3 \%)$ lived in rural places, while only (18.7\%) lived in urban places.
Table (2): In relation to factor affection perception of nurse students about role transition, this table showed that organizational factors had the highest mean score followed by personal factors. While nursing staff shortage and social factors had the lowest mean scores.

Table (3): Shows that more than two thirds of nurse students $(71.5 \%)$ had moderate agreement regarding organizational factors, also more than half of nurse students had moderate perception level regarding personal and educational factors $(57.5 \%, 52.8 \%)$ respectively. Also, more than half of them had high agreement to nursing staff shortage and professional accountability and commitment factors $(60.1 \%, 50.3 \%)$ respectively.

Figure (3): Clarifies that $(80.3 \%)$ of nurse students had moderate agreement regarding factors affecting role transition. Table (4): Illustrates that there were statistically significant relations between age, gender and marital status and total perception level about factors affecting nurse students' role transition perception. As regards the students' residence, this table shows there was no statistically significant relation between total perception level and students' residence. Table (5): Shows that there was no statistically significant relation between perception total level and type of graduation before faculty enrolment of nursing students. 
Table (1): Distribution of demographic characteristics of nurse students ( $n=193$ )

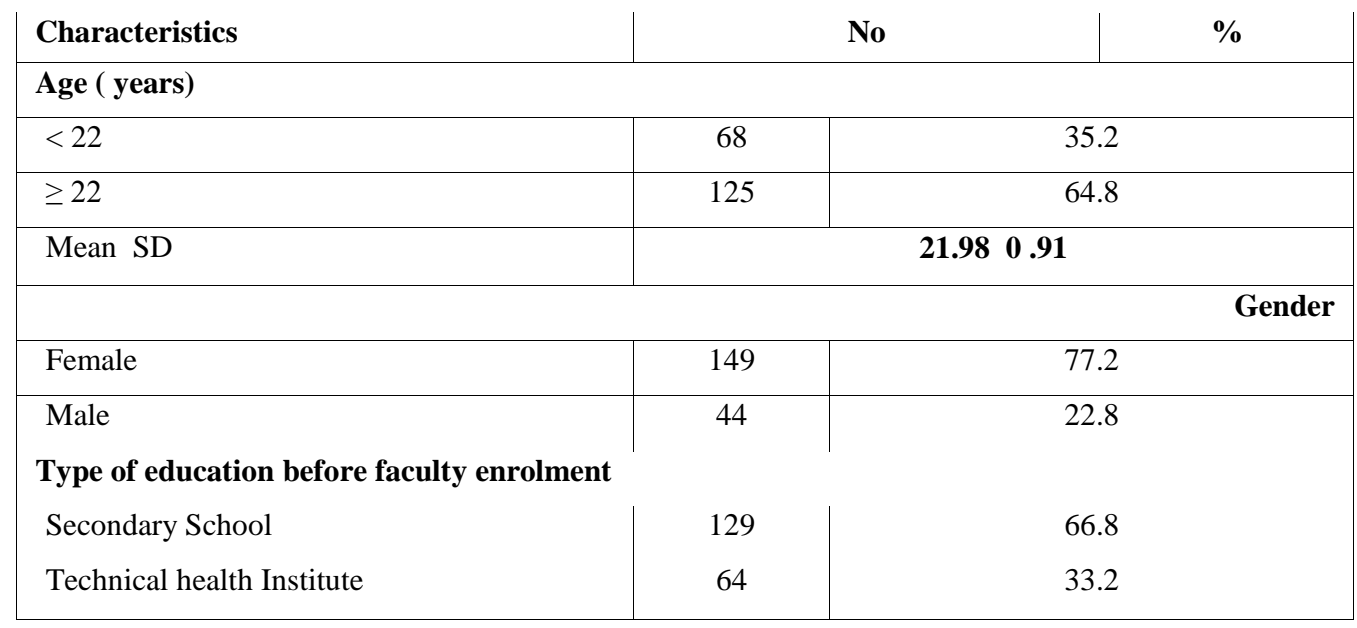

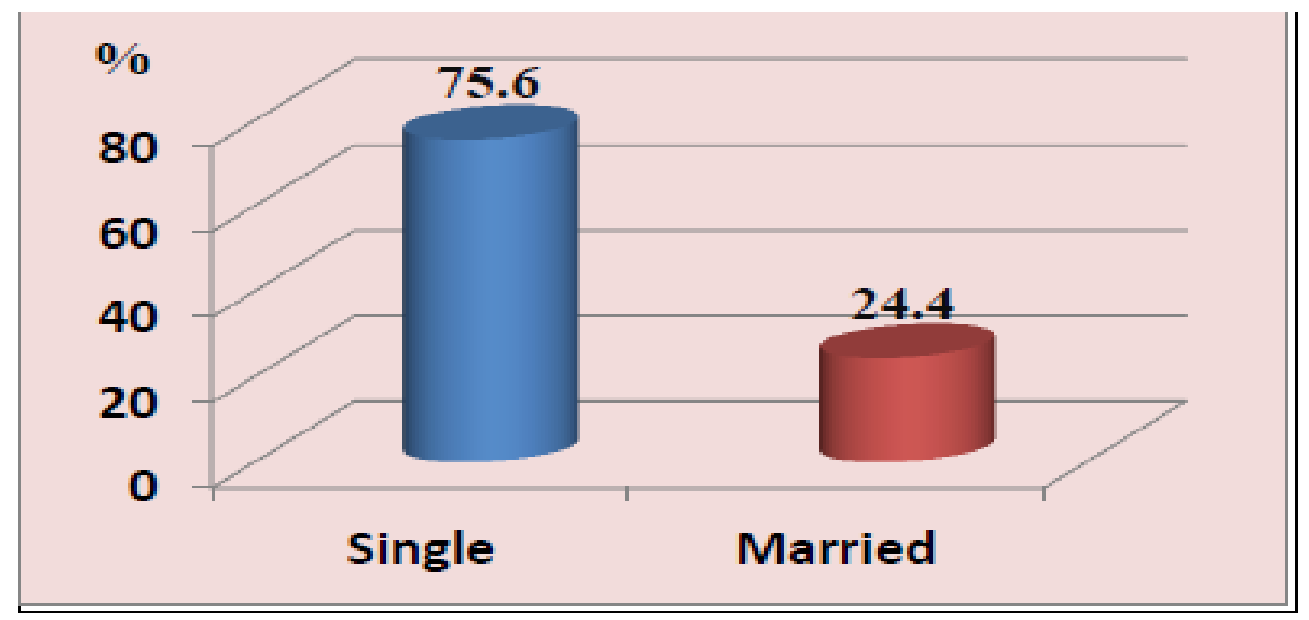

Figure (1): Distribution of the studied nurse students according to marital status $(n=193)$ 
Factors Affecting Nurse Students' Perception Regarding Role Transion at Faculty of Nursing Benha Univesity

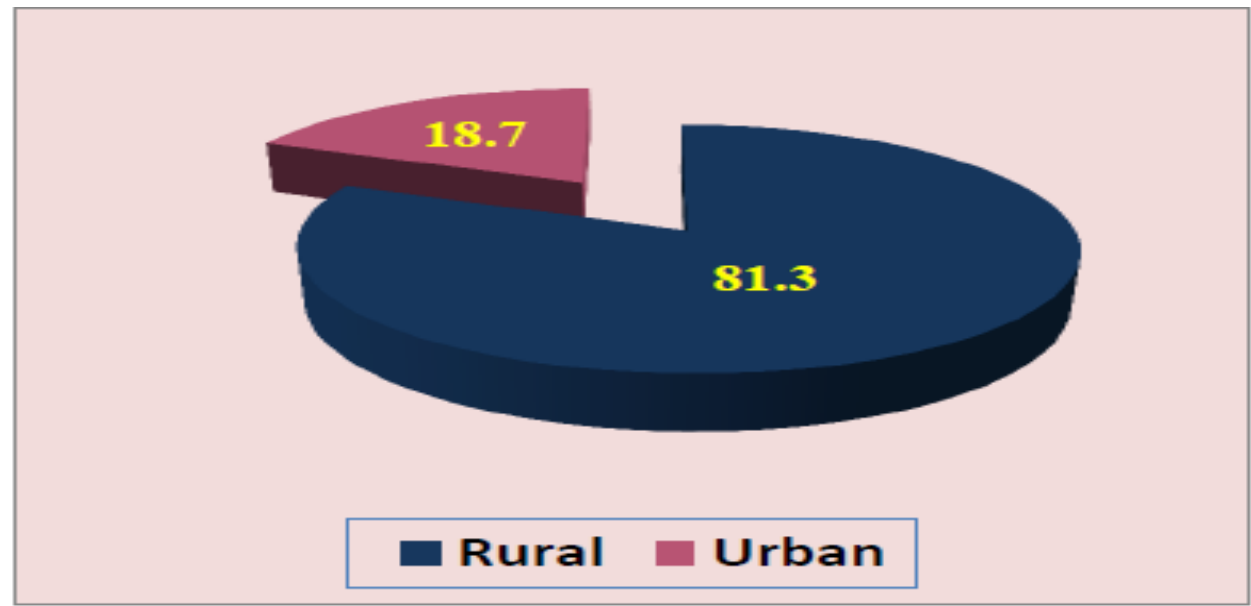

Figure (2): Distribution of the studied nurse students according to their place of residence $(n=193)$

Table (2): Mean score of the nurse students' total perception of factors which affect role transition perception $(n=193)$.

\begin{tabular}{|c|c|c|c|c|}
\hline $\begin{array}{l}\text { Factors } \\
\text { Personal } \\
\end{array}$ & $\begin{array}{c}\text { No. of } \\
\text { items } \\
14\end{array}$ & $\begin{array}{c}\text { Minimum } \\
0.00 \\
\end{array}$ & $\begin{array}{c}\text { Maximum } \\
26.00 \\
\end{array}$ & $\begin{array}{l}\text { Mean SD } \\
12.925 .26 \\
\end{array}$ \\
\hline Social & 4 & 0.00 & 8.00 & 4.562 .25 \\
\hline Students satisfaction & 5 & 0.00 & 10.00 & 6.052 .50 \\
\hline Educational & 9 & 0.00 & 18.00 & 9.843 .61 \\
\hline Organizational & 24 & 12.00 & 42.00 & 28.135 .36 \\
\hline Expected level of support & 5 & 0.00 & 10.00 & 6.152 .47 \\
\hline $\begin{array}{l}\text { Professional account- ability } \\
\text { and commitment }\end{array}$ & 9 & 2.00 & 18.00 & 11.683 .53 \\
\hline Nursing staff shortage & 2 & 0.00 & 4.00 & 2.781 .18 \\
\hline
\end{tabular}

Table (3): Levels of perception among nurse students regarding factors affecting role transition $(n=193)$

\begin{tabular}{|l|c|c|c|c|c|c|}
\hline \multirow{2}{*}{\multicolumn{1}{|c|}{ Factors }} & \multicolumn{3}{c|}{ Perception levels } \\
\cline { 2 - 7 } & \multicolumn{2}{|c|}{ High } & \multicolumn{2}{c|}{ Moderate } & \multicolumn{2}{c|}{ Low } \\
\cline { 2 - 7 } & No & $\%$ & No & $\%$ & No & $\%$ \\
Personal factors & 33 & 17.1 & 111 & 57.5 & 49 & 25.4 \\
Social factors & 72 & 37.3 & 81 & 42.0 & 40 & 20.7 \\
\hline Students satisfaction & 83 & 43.0 & 75 & 38.9 & 35 & 18.1 \\
\hline Educational factors & 64 & 33.2 & 102 & 52.8 & 27 & 14.0 \\
\hline Organizational factors & 51 & 26.4 & 138 & 71.5 & 4 & 2.1 \\
Expected level of support & 92 & 47.7 & 73 & 37.8 & 28 & 14.5 \\
Professional accountability and commitment & 97 & 50.3 & 88 & 45.6 & 8 & 4.1 \\
\hline Nursing staff shortage & 116 & 60.1 & 47 & 24.4 & 30 & 15.5 \\
\hline
\end{tabular}


Table (4): Relation between total perception levels and demographic Characteristics of the studied nurse students $(n=193)$.

\begin{tabular}{|c|c|c|c|c|c|c|c|c|}
\hline \multirow{3}{*}{$\begin{array}{l}\text { Demographic } \\
\text { Characteristics }\end{array}$} & \multicolumn{6}{|c|}{ Total perception levels } & \multirow{3}{*}{$\begin{array}{c}\text { Test of } \\
\text { significance }\end{array}$} & \multirow{3}{*}{$P$ - value } \\
\hline & \multicolumn{2}{|c|}{$\begin{array}{l}\text { High } \\
\mathbf{n}=31\end{array}$} & \multicolumn{2}{|c|}{$\begin{array}{c}\text { Moderate } \\
\mathbf{n}=155\end{array}$} & \multicolumn{2}{|c|}{$\begin{array}{l}\text { Low } \\
n=7\end{array}$} & & \\
\hline & No & $\%$ & No & $\%$ & No & $\%$ & & \\
\hline \multicolumn{9}{|l|}{ Age )yearsذ( } \\
\hline $22>$ & 18 & 58.1 & 47 & 30.3 & 3 & 42.9 & FET & \multirow[t]{2}{*}{$0.012 *$} \\
\hline $22 \leq$ & 13 & 41.9 & 108 & 69.7 & 4 & 57.1 & 8.898 & \\
\hline \multicolumn{9}{|l|}{ Gender } \\
\hline Female & 27 & 87.1 & 120 & 77.4 & 2 & 28.6 & FET & \multirow[t]{2}{*}{$0.004^{*}$} \\
\hline Male & 4 & 12.9 & 35 & 22.6 & 5 & 71.4 & 11.134 & \\
\hline \multicolumn{9}{|l|}{ Marital Status } \\
\hline Single & 29 & 93.5 & 110 & 71.0 & 7 & 100.0 & FET & \multirow[t]{2}{*}{$0.009^{*}$} \\
\hline Married & 2 & 6.5 & 45 & 29.0 & 0 & 0.0 & 9.488 & \\
\hline \multicolumn{9}{|l|}{ Place of residence } \\
\hline Rural & 26 & 83.9 & 125 & 80.6 & 6 & 85.7 & FET & \multirow[t]{2}{*}{0.874} \\
\hline Urban & 5 & 16.1 & 30 & 19.4 & 1 & 14.3 & 0.268 & \\
\hline
\end{tabular}

* Statistical significant difference $(\mathrm{P} \leq \mathbf{0 . 0 5})$

FET $=$ Fisher Exact Test

Table (5): Relation between total perception levels and type of graduation of the studied nurse students $n=(193)$

\begin{tabular}{|c|c|c|c|c|c|c|}
\hline \multirow[t]{2}{*}{$\begin{array}{l}\text { Type of graduation } \\
\text { Total perception } \\
\text { Levels }\end{array}$} & \multicolumn{2}{|c|}{$\begin{array}{c}\text { Secondary } \\
\text { School } \\
n=129\end{array}$} & \multicolumn{2}{|c|}{$\begin{array}{c}\text { Technical } \\
\text { health } \\
\text { Institute } \\
\mathbf{n}=64\end{array}$} & \multirow[t]{2}{*}{$\begin{array}{c}\text { Test of } \\
\text { significance }\end{array}$} & \multirow[t]{2}{*}{$P$-value } \\
\hline & No & $\%$ & No & $\%$ & & \\
\hline High & 14 & 10.9 & 17 & 26.6 & \multirow{3}{*}{$\begin{array}{l}\text { FET } \\
7.831\end{array}$} & \multirow[t]{3}{*}{0.020} \\
\hline Moderate & 110 & 85.2 & 45 & 70.3 & & \\
\hline Low & 5 & 3.9 & 2 & 3.1 & & \\
\hline
\end{tabular}

* Statistical significant difference $(\mathrm{P} \leq \mathbf{0 . 0 5})$

\section{FET $=$ Fisher Exact Test}

\section{Discussion}

Transition from nurse students to practicing nurse can be a challenging and stressful for new nurses. The health care organizations must provide transition programs to support nurse students' perception through this vulnerable time and to assist in increasing graduates' job satisfaction and retention rates. However, no systematic review of transition program outcomes has been undertaken to 
determine the impact of these programs on improving satisfaction levels and on easing the challenges faced by nursing graduates in their new roles as registered nurses (Phillips et al., 2014).

The present study aimed to assess factors affects nurse students' perception regarding role transition at faculty of nursing- Benha University.

In relation to factors affecting perception of nurse student about role transition; the study results revealed that distribution of socio-demographic characteristics of the studied sample, the highest percentage of nursing students regarding to the age, about two thirds of nursing students were $\geq 22$ years old, and the highest percentages of nursing students related to sex were females.

The results of the study agree with Ozdemir et al. (2008) who conducted study about nursing students' perceptions of male nursing role. Who reported that the highest percentages of nursing students were females and this shows that nursing profession is more female dominant.

As regarding to marital status, about three quarters of studied nursing students were single. The result of the study was in agreement with Doody et al (2012) who reported that, the majority of studied sample were single.

As regarding to residence, the majority of studied nursing students have a rural residence. For my perspective that nursing students from rural residence have a higher perception for their role than nursing students from urban residence.

More than two third of nurse students agreed upon organizational factors is the most factors affecting role transition. This may be due to unavailability of equipment and supplies, unsafe work environment, lack of welfare and lack of support from families, faculty and hospital. These contributed with factors affecting role transition.

On the same hand Bratt and Felzer (2012) who conducted a study about Predictors of new graduate nurses' organizational commitment during a nurse residency program reported that, nurse student is considered one of the health care team. Who are expected to observe and communicate with patients and participate as a member of a team in the organization. Moreover, nurse students try to meet the needs of the parties requesting care and works according to the professional standards and values. Those bases actions on theoretical and practical knowledge as well as on the results of scientific research.

These results coincided with (OlsonSitki et al., 2012) who conducted study about evaluating the impact of a nurse residency program for newly graduated registered nurses who reported that, lack of effective orientation program was a barrier to our participants preparation for transition and also nursing education must continually developed to meet the requirements of patient care.

On the same line Zinsmeister and Schafer (2009) who conducted a study about the exploration of the lived experience of the graduate nurse making the transition to registered nurse during the first year of practice reported that, organizational stressors include lack of support within the unit and from management, as well as a lack of resources such as time, guidance, and available equipment to accomplish daily nursing tasks. 
Organizational stressors unique to today's new graduate nurses include a chaotic workplace characterized by nursing shortage and high patient acuity. These stressors may lead to acute moral distress, depression and role transition shock. Adapting to a new organization and professional responsibilities is a learning process that requires forging new definitions of one's self. The organization has an active role in socializing new graduates (Al-Mahmoud et al., 2013). Moreover, Dingley and Yoder (2013) reported that, the environment that nurse students are entering nowadays are complex and constantly changing with continuous new demands.

Furthermore, Dingley and Yoder (2013) who conducted a study about the public health nursing work environment and concluded that, work environment influence commitment, job satisfaction and the intention to stay and is influenced by the organizational culture, defined goals, norms, values and practices of an organization that guide the thinking and behavior of its group members.

The present study revealed that relation between total perception level and characteristics of the studied sample. The current study found that there were statistically significance relation between age and gender of nurse students and total perception level. This may be related to nurse students female perceived their roles more than nurse students' male sample, because society believed that nursing career is feminine. In agreement with these results, Tastan et al., (2011) reported that there are differences of perceptions of role related to some personal factors such as gender. Female students had significantly more positive perception scores for their role than males.

On the other hand Al-Mahmoud et al. (2013) who conducted a study about assessing factors leading to role transition shock among intern students reported that male nurse student perceived their roles more than female nurse student.

The present study revealed that there is statistical significant relation between perception levels according to type of education before faculty enrolment with moderate level in secondary school.

From the researcher perspective, nurse students graduated from secondary school perceived their role more than graduated from technical institute. It is unexpected result, may be students with secondary certificate had not experience about clinical environment and hospital. Also their number is more than number of students with diploma degree and they hope to change society image about nursing profession.

\section{Conclusion}

After ongoing the present study this finding answer the research question indicated that more than two third of nurse students had moderate perception regarding organizational factors, also more than half of nurse students had moderate perception regarding personal and educational factors. More than half of nurse students had highly agreement to nursing staff shortage and professional accountability and commitment. There were statistically significance relations between age, gender and marital status and total agreement level about factors affecting nurse students' role transition perception.

\section{Recommendations}

In the light of the findings obtained from the present study, the following suggestions are recommended: 
- Conduct an orientation program for nurse students before internship program and before each training period to explain objectives, roles and responsibilities and discuss nurse students' expectation.

- Promote collaboration between hospital staff and faculty staff to facilitate nurse students' induction to real work world through support, empowerment and motivation in clinical area.

- Creating healthy training environment is highly needed for new nurses during role transition.

- Assess the clinical learning needs of nurse students periodically and develop a training program for them to the challenges facing in clinical practice.

- Establish preceptors ship program in Benha-university and hospitals is vital to assisting nurse students in role transition from student to graduate.

- Clarify for the role expectations by using role models, role repetition, preceptors, mentors to keep working with professional standards and values.

- Further studies are suggested as:

- Relationship between role transition process and stress among nurse students.

- Nurse students versus faculty staff satisfaction regarding clinical training environment.

\section{References}

Al-Mahmoud, S., Dorgham, S. \& Abd El- Mageed, M. (2013): Relationship between nurse interns' satisfaction regarding Internship program and clinical competence. Medical Journal of Cairo University, 81(2): 151-161.

Azimian, J., Negarandeh, R. \& FakhrMovahedi, A. (2014): Factors affecting nurses' coping with transition: an exploratory qualitative study. Global Journal of Health Science, 6 (6): 21-32

Bennett, P., Barlow, V., Brown, J. \& Jones, D. (2012): What do graduate registered nurses want from jobs in rural/remote Australian communities. Journal of Nursing Management, 20 (4): 485-490.

Bratt, M., \& Felzer, H. (2012): Predictors of new graduate nurses' organizational commitment during a nurse residency program. Journal for Nurses in Staff Development, 28 (3): 108-119.

Dingley, J. \& Yoder, L. (2013): The public health nursing work environment: review of the research literature", Journal of Public Health Management and Practice, 19 (4), 308321.

Doody, O., Tuohy, D., \& Deasy, C. (2012): Final-year student nurses' perceptions of role transition. British Journal of Nursing, 21 (11): 684-688.

Edwards R. (2013): Sampling and choosing cases in qualitative research: A realist approach. International Journal of social Research Methodology, 17 (3): 320-322.

Jessica, Y. \& Crossman, L. (2015): New nurse transition success through aligning multiple identities. Journal of Health Organization and Management, 29 (7): 1098-1114. 
Kelly, J. \& Aern, K. (2009): Preparing nurses for practice: a phenomenological study of the new graduate in Australia. J. Clin. Nurs. 18 (6), 910-918.

Lee, S., Park, S. \& Jeong, S. (2014): Nursing core competencies needed aged care reform, Australia Government Department of Social Services Retrieved from. Australian Journal of Nursing, 20 (14): 604-608.

MacLellan, L., Higgins, I., \& LevettJones, T. (2014): Medical acceptance of the nurse practitioner role in Australia: A decade on. Journal of the American Association of Nurse Practitioners. 43 (2): 271-278.

Maten-Speksnijder, A., Grypdonck, A., Meurs, P. \& Van Staa, A. (2015): Driven by ambitions: The nurse practitioner's role transition in Dutch hospital care. Journal of Nursing Scholarship, 23 (3): 1-11.

Meleis, A. (2010): Transitions theory: middle-range and situation-specific theories in nursing research and practice. New York, NY: Springer Publishing Company. Pp. 1023.

O'Shea, M. \& Kelly, B. (2007): The lived experiences of newly qualified nurses on clinical placement during the first six months following registration in the Republic of Ireland, Journal of Clinical Nursing 16 (4), 1534-1542.

Olson-Sitki, K., Wendler, M. \& Forbes, G. (2012): Evaluating the impact of a nurse residency program for newly graduated registered nurses. Journal for Nurses in Staff Development, 28 (3): 156-162.

Ozdemir, A., Akansel, N. \& Tunk, G. (2008): Gender and Career; female and male nursing students perception in turkey. Health Science Journal; 2 (3): 153-161.

Parker, V., Giles, M., Lantry, G. \& McMillan, M. (2014): New graduate nurses' experiences in their first year of practice. Journal of Nurse Education Today, 34 (3): 150-156.

Phillips, C., Kenny, A., Esterman, A. \& Smith, C. (2014): A secondary data analysis examining the needs of graduate nurses in their transition to a new role. Journal of Nurse Educ. Pract. 14 (2), 107-111.

Tastan, V., Unver, S. \& Hatipoglu, B. (2011): An analysis of the factors affecting the transition period to professional roles for newly graduated nurses in Turkey. International Nursing Review, 60 (3): 405-412.

Zinsmeister, L., \& Schafer, D. (2009): The exploration of the lived experience of the graduate nurse making the transition to registered nurse during the first year of practice. Journal for Nurses in Staff Development, 25(1): 28-34. 